\title{
Neck abscess secondary to pocket shot intravenous drug abuse
}

\author{
Kamal Kant Sahu (ㄷ), Nicholas Tsitsilianos, Ajay Kumar Mishra, \\ Nuttanun Suramaethakul, George Abraham
}

Department of Internal Medicine, Saint Vincent Hospital, Worcester, Massachusetts, USA

\section{Correspondence to \\ Dr Kamal Kant Sahu; \\ Kamalkant.Sahu@}

stvincenthospital.com

Accepted 15 February 2020

Check for updates

(c) BMJ Publishing Group Limited 2020. No commercial re-use. See rights and permissions. Published by BMJ.

\begin{tabular}{l}
\hline To cite: Sahu KK, \\
Tsitsilianos N, Mishra AK, \\
et al. BMJ Case Rep \\
2020;13:e234033. \\
doi:10.1136/bcr-2019- \\
234033
\end{tabular}

\section{DESCRIPTION}

A 37-year-old woman presented to us for the complaints of pain and swelling over her right side of the neck and high spiking fever for the last 3 days. Her previous medical history was significant for intravenous drug abuse and she reported injecting heroin and methamphetamine by mixing with tap water to the right side of her neck 2 days before having these symptoms. Neck examination showed a large reddish, swelling approximately $10 \times 10 \mathrm{~cm}$ in maximum dimension. Palpation showed tenderness, warmth and positive fluctuation suggesting a possible underlying pus collection (figure 1A). CT neck was done which showed a thick rim-enhancing, loculated fluid collection in the lateral right sternocleidomastoid intramuscular muscle measuring $2.6 \times 2.6 \times 5.3 \mathrm{~cm}$ suggesting an abscess with overlying cellulitis (figure 1B-E). An ultrasonography-guided aspiration of the $30 \mathrm{~mL}$ of purulent fluid was done in almost its entirety, consisting of frank pus mixed with blood (figure 1C). Her blood cultures were sterile, and the aspiration fluid culture was positive for methicillinsensitive Staphylococcus aureus. She was initiated on cefazolin $2 \mathrm{~g}$ intravenous every 8 hours, planned for 4 weeks. Also, she was counselled for her illicit drug use and its health hazards, given adequate social support to quit drug abuse and educated for using sterile precautions. Last follow-up after completion of antibiotics showed clinical improvement with complete resolution of visible swelling of the neck. The patient is currently enrolled in drug addiction rehabilitation programme

Intravenous drug abusers (IVDAs) pose a significant threat to their life and to the community secondary to the intravenous drug abuse and its related complications. ${ }^{1}$ IVDAs most commonly use accessible sites for injecting illicit drugs like veins of upper and lower extremities. Many times, due to multiple usages, superficial veins over arms get thrombosed. In a desperate attempt to get access, they end up experimenting with dangerous techniques, one of them is known as 'pocket shot'. This method involves an effort to access major veins of the neck jugular, subclavian or brachiocephalic veins by injecting in the supraclavicular fossa. ${ }^{2}$ The term 'pocket shot' comes from the anatomical location, supraclavicular fossa commonly being referred to as a pocket by IVDAs. ${ }^{3}$ The two commonly referred pockets are either triangle formed between the two sternocleidomastoid muscle bellies with clavicle or a triangle located at extreme lateral to the sternocleidomastoid muscle above the clavicle.

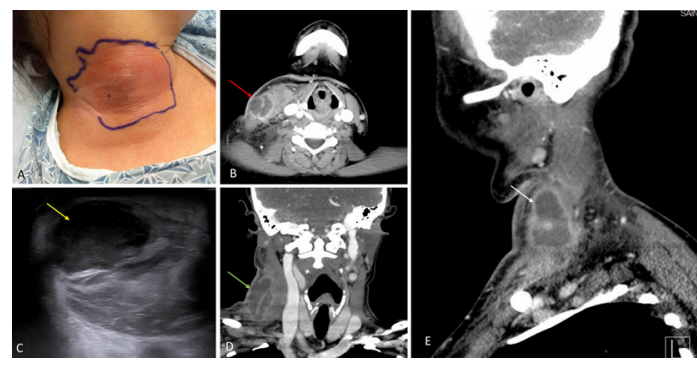

Figure 1 (A) Clinical picture showing swelling of the neck at the site of injection. (B) CT neck axial view showing loculated pus collection. (C) Ultrasonography (USG) of the neck confirmed a hypoechoic spherical collection of echogenic fluid with well-defined borders. (D, E) CT coronal view (D) and sagittal view (E) confirming the abscess in the sternocleidomastoid muscle measuring $2.6 \times 2.6 \times 5.3 \mathrm{~cm}$.

Similarly, another commonly used site is the femoral vein, commonly known as 'Groin hit'. ${ }^{4}$ However, pocket shooters are more vulnerable to develop complications owing to the proximity of major vessels in the neck and can lead to fatal complications of the cardiovascular and pulmonary systems like pneumothorax, mediastinitis, osteomyelitis, haemothorax and empyema. ${ }^{5}$ IVDAs can choose to hit these areas on their own or can even hire other IVDAs, referred to as 'Street docs' or 'Hitman' to perform injections. Maliphant et al conducted a patient survey on 47 IVDAs using femoral veins for accessibility ('Groin Hit'). They found the mean time interval of first intravenous use and first use of

\section{Learning points}

- Mediastinal and cardiovascular complications like pneumomediastinum, pneumothorax, vertebral body osteomyelitis and aortic dissection are potential complications in intravenous drug abusers (IVDAs) who engage in 'pocket shot'.

- IVDAs have different location of abscess formation as compared with non-IVDAs and knowledge of these differences is essential while managing 'pocket shot' IVDAs.

- 'Pocket shot' IVDAs are a special category of IVDAs that need special attention with regards to educating the patients about the complications and fatality of the injecting drugs on central veins. 
groin as 7.0 years. Except for one patient, all others had used at least one area before using groin. Common problems reported by IVDAs were fibrosis, occlusion, pain, sinus formation and deep venous thrombosis. Similar studies among 'pocket shot' IVDAs is lacking however Tamir et al did a study comparing deep neck infections (DNI) in IVDAs versus non-IVDAs. ${ }^{6}$ Out of 136 DNI patients, 20 (15\%) were due to intravenous drug abuse. Similarly, they reported more frequent abscess formation in the IVDA subgroup as compared with non-IVDA subgroup $(80 \%$ vs $68 \%, \mathrm{p}$ value $=0.04)$. Also, they found a difference in the anatomic location/distribution of a DNI in the IVDA versus nonIVDA subgroup. Anterior triangle deep to the sternocleidomastoid muscle and posterior triangle were the most common sites in IVDA subgroup as compared with non-IVDA subgroup who had multiple space infection and submandibular and submental triangle as the most common involved sites. Interestingly, despite having more comorbidities and a late presentation, DNI in both subgroups had similar outcomes in terms of laboratory data, microbiology cultures and disease course. Any collection or mass in the orbit and neck, paravertebral region and paraspinal space need emergent care to prevent neurological catastrophe. ${ }^{7-10}$

Contributors KKS performed management, review and manuscript writing. NT did management, literature search and grammar edit. AKM and GA reviewed, edited and wrote the manuscript. NS and GA performed specialist consult, review and critical comments.

Funding The authors have not declared a specific grant for this research from any funding agency in the public, commercial or not-for-profit sectors.
Competing interests None declared.

Patient consent for publication Obtained.

Provenance and peer review Not commissioned; externally peer reviewed.

\section{ORCID iD}

Kamal Kant Sahu http://orcid.org/0000-0002-0382-6882

\section{REFERENCES}

1 Sahu KK, Mishra A, Naraghi L. Erythema ab igne as a complication of cannabinoid hyperemesis syndrome. BMJ Case Rep 2019;12:e227836.

2 McCarroll KA, Roszler MH. Lung disorders due to drug abuse. J Thorac Imaging 1991;6:30-5.

3 Wisdom K, Nowak RM, Richardson $\mathrm{HH}$, et al. Alternate therapy for traumatic pneumothorax in "pocket shooters". Ann Emerg Med 1986;15:428-32.

4 Maliphant J, Scott J. Use of the femoral vein ('groin injecting') by a sample of needle exchange clients in Bristol, UK. Harm Reduct J 2005;2:6.

5 McCarroll KA, Roszler MH, Donovan KR. The "Pocket shot": Complications of intravenous drug abuse. Emerg Radiol 1994;1:183-94.

6 Tamir SO, Marom T, Len A, et al. Deep neck infections in cervical injection drug users. Laryngoscope 2015;125:1336-9.

7 Sahu KK, Rapose A, Bhandari B, et al. Letter to the Editor Regarding "Craniocervical Osteoradionecrosis Treated with Neoadjuvant and Adjuvant Hyperbaric Oxygen in Combination with Posterior Spinal Fusion". World Neurosurg 2019;129:541-3.

8 Sahu KK, Chastain I. A rare case of Holocord spinal epidural abscess. QJM 2019:pii: hcz291.

9 Sahu KK, Sanamandra P, Jeyaraman P, et al. Unusual cause of cord Compression-A Pressing issue for neurosurgeons. World Neurosurg 2016;92:565-7.

10 Sahu KK, Malhotra P. Re: "Granulocytic Sarcoma of the Orbit Presenting as a Fulminant Orbitopathy in an Adult with Acute Myeloid Leukemia". Ophthalmic Plast Reconstr Surg 2015;31:421.

Copyright 2020 BMJ Publishing Group. All rights reserved. For permission to reuse any of this content visit

https://www.bmj.com/company/products-services/rights-and-licensing/permissions/

BMJ Case Report Fellows may re-use this article for personal use and teaching without any further permission.

Become a Fellow of BMJ Case Reports today and you can:

- Submit as many cases as you like

- Enjoy fast sympathetic peer review and rapid publication of accepted articles

- Access all the published articles

- Re-use any of the published material for personal use and teaching without further permission

Customer Service

If you have any further queries about your subscription, please contact our customer services team on +44 (0) 2071111105 or via email at support@bmj.com.

Visit casereports.bmj.com for more articles like this and to become a Fellow 